\title{
O desenvolvimento de emoções e sentimentos e a formação de valores
}

\author{
Development of emotions and feelings and value formation
}

\author{
Afonso Mancuso de Mesquita ${ }^{1}$ \\ Jéssica Bispo Batista² \\ Márcio Magalhães da Silva
}

\begin{abstract}
RESUMO
O presente estudo busca contribuir para a compreensão do desenvolvimento emocional e da formação de valores na sociedade capitalista, sintetizando trabalhos recentes sobre o assunto baseados no materialismo histórico-dialético e na psicologia históricocultural. Trata-se de uma aproximação do tema que abarca a gênese $e$ as especificidades das emoções e dos sentimentos na atividade humana, bem como a periodização do desenvolvimento dos processos afetivos e suas relações com a formação de valores sociais. Por fim, partindo da constatação de que a escola tem se preocupado em promover um tipo de desenvolvimento emocional e moral que garante sustentação à sociedade capitalista, aponta-se a necessidade de desenvolver alternativas críticas ao modelo hegemônico, considerando que a dimensão afetiva é um elemento indissociável dos processos reflexivos e indispensável para a transformação da escola e da sociedade.
\end{abstract}

\begin{abstract}
This paper intends to contribute to the understanding of emotional development and value formation in capitalist society, by gathering recent works on the subject based on historical-dialectical materialism and historical-cultural psychology. It is an attempt to discuss the theme that encompasses the genesis and particularities of emotions and feelings in human activity, as well as the age periodization of affective processes and their relations with social values formation. Finally, considering that school has been concerned with promoting a kind of emotional and moral development that guarantees support to the capitalist society, the paper points out the need to develop critical alternatives to the hegemonic model, considering that the affective dimension is an element inseparable from reflexive processes and indispensable for the transformation of school and society.
\end{abstract}

Keywords: Emotions. Feelings. Values. Historical-cultural psychology.

Palavras-chave: Emoções. Sentimentos. Valores. Psicologia historico-cultural.

${ }^{1}$ Professor assistente da Universidade Estadual de Feira de Santana (UEFS). E-mail: ammesquita@uefs.br.

${ }_{2}^{2}$ Psicóloga e mestre em Educação Escolar pela Faculdade de Ciências e Letras de Araraquara da Universidade Estadual Paulista (Unesp). E-mail: jebispob@gmail.com.

${ }^{3}$ Professor adjunto da Universidade Federal de Lavras (UFLA). E-mail: marcio.dasilva@ufla.br. 


\section{Introdução}

[...] acima de tudo procurem sentir no mais profundo de vocês qualquer injustiça cometida contra qualquer pessoa em qualquer parte do mundo. É a mais bela qualidade de um revolucionário. (Che Guevara) ${ }^{4}$

O estudo sobre o desenvolvimento de emoções e sentimentos relacionado à formação de valores na perspectiva da psicologia histórico-cultural justifica-se pela necessidade social de compreender o papel desses processos na formação da personalidade e a intrínseca relação com os encaminhamentos éticos advindos da incorporação de valores sociais. Há fatos recentes que clamam por uma teoria das emoções consistente e coerente com o materialismo histórico-dialético, fundamento da psicologia histórico-cultural, como, por exemplo, propostas de educação emocional e moral nas escolas com finalidades adaptacionistas, denúncias de manipulação do comportamento de eleitoras/es em diferentes países com base em informações sobre a personalidade de usuárias/os das redes sociais obtidas ilegalmente, ou a disputa ideológica em torno de valores fundamentais, como o direito ao desenvolvimento afetivo-sexual singular, ou ainda um conservadorismo anacrônico em relação à normatização dos papéis de gênero. Esses são somente exemplos que revelam a importância da elaboração de teses consistentes que possibilitem pensar o desenvolvimento emocional e a formação de valores na sociedade capitalista brasileira contemporânea, objetivo que só pode se efetivar por meio de um grande esforço coletivo, para o qual trabalhos recentes (Batista, 2019; Mesquita, 2018; Silva, 2018) aqui sintetizados pretendem contribuir.

Sobre a teoria das emoções, Vigotski afirma que "naturalmente, a construção de tal teoria não pode se resolver em apenas um estudo, ainda mais de caráter abstrato, mas que, como em qualquer tarefa complexa, também aqui se requer uma divisão de trabalho. Não há dúvida de que esta teoria apenas pode se

\footnotetext{
4 "[...] sobre todo, sean siempre capaces de sentir en lo más hondo cualquier injusticia cometida contra cualquiera en cualquier parte del mundo. Es la cualidad más linda de un revolucionario". Carta de despedida de Ernesto 'Che' Guevara a seus filhos.
} 
criar depois de uma série de investigações"5 (Vigotsky, 2004b, p. 58). Tais investigações demandam não apenas estudos teóricos, mas também empíricos, o que se institui como um desafio ainda maior, considerando-se os limites institucionais para a realização de pesquisas no Brasil, especialmente no campo das ciências humanas, agravados em razão do fundamento marxista da psicologia histórico-cultural.

\section{Emoções e sentimentos: da natureza à cultura}

$\mathrm{Na}$ natureza, as emoções são processos decorrentes da avaliação, pelo organismo, da sua correlação imediata com o meio, e sinalizam situações favoráveis ou desfavoráveis à sobrevivência. Determinadas condições externas e internas do organismo combinadas provocam reações comportamentais (bioquímicas, fisiológicas, expressivas e motoras) que garantiram no processo evolutivo a sobrevivência da espécie humana. As emoções são, portanto, na sua gênese, reações do organismo à avaliação contínua da sua relação com o meio e compreendem alterações que ocorrem diante da apreensão sensório-perceptual da realidade, incluindo sensações provenientes do exterior e do interior do organismo (sensações exteroceptivas, interoceptivas e proprioceptivas). Nessa perspectiva, a emoção corresponde ao conjunto formado pelo seu objeto, apreendido sensório-perceptualmente, e pelas sensações corporais decorrentes das alterações orgânicas causadas para facilitar a ocorrência de um comportamento externo adaptativo, necessário à manutenção da vida.

A conversão desse processo natural elementar em processo cultural complexo ocorre, como nos demais processos psicológicos que orientam e regulam a conduta humana, pela interposição de signos na relação entre sujeito e objetos da realidade. Signos são, de acordo com Vigotski (2004a), instrumentos culturais dotados de significados dirigidos à regulação da conduta, que atuam inicialmente nas relações intersubjetivas e transformam o psiquismo individual ao serem internalizados, convertendo-se em processos intrapsíquicos. Nesse sentido, a apropriação da cultura transforma qualitativamente as formas naturais e

${ }^{5}$ Todas as citações de obras em espanhol foram traduzidas e estão sob responsabilidade da/os autora/es. 
espontâneas de comportamento em formas volitivas. Sendo assim, os processos culturais complexos, incluindo as emoções, desenvolvem-se a partir de processos sociais, coletivos, o que permite supor que as emoções culturais são, antes de serem reações de um indivíduo a determinados objetos, padrões culturais de reação a esses objetos.

A história do desenvolvimento das emoções se vincula à história da atividade de produção da realidade. Como ser social, o ser humano responde a necessidades forjadas na relação ativa com o mundo, satisfazendo-as por meio da atividade consciente. Para Leontiev (2017), as necessidades despontam como estados de carência indiferenciados, manifestando-se como desejos e tendências que se realizam a depender das possibilidades objetivas e subjetivas de saná-las. Nesse percurso, as emoções e sentimentos impulsionam ou inibem a atividade e ao mesmo tempo são desdobramentos de sua realização, na medida em que validam ou invalidam os seus resultados. A atividade funda, portanto, o desenvolvimento das emoções propriamente humanas e o sentido primordial desse desenvolvimento é a regulação da conduta voltada para a satisfação de necessidades.

$\mathrm{Na}$ ontogênese, as emoções só se tornam um elemento de regulação da atividade como produto do desenvolvimento que se inicia imediatamente após o nascimento. A cada novo período do desenvolvimento novas formações psíquicas são gestadas, as quais provocam transformações no comportamento da criança. Por esse motivo é imprescindível, no estudo das emoções, compreender como elas adquirem sua função reguladora, excitadora ou inibidora da atividade, a partir do entendimento do processo de complexificação da estrutura e da dinâmica da própria atividade. A periodização do desenvolvimento em geral, bem como do emocional especificamente, corrobora um princípio metodológico do materialismo histórico-dialético, pelo qual o estudo científico das emoções e dos sentimentos demanda a análise desse objeto como processo histórico, no decurso dos períodos do desenvolvimento infantil, explicitando sua origem e explicando suas mudanças a partir das transformações na estrutura e dinâmica da atividade que vincula o indivíduo à realidade. 
A partir do exposto sobre as emoções na natureza, a emoção humana pode ser compreendida como os estados do corpo na atividade concreta, dotados de significado e enredo social. Examinando a dinâmica e a estrutura da atividade, identifica-se que as emoções estão vinculadas ao plano concreto (social e histórico) e se expressam na vivência de uma ação concreta. Já em Vigotski havia a defesa, apoiada no pensamento de Espinosa, de que "a emoção não é simplesmente a soma das sensações das reações orgânicas mas, principalmente, uma tendência a atuar em uma direção determinada" (Vigotsky, 2004b, p. 40). Nessa perspectiva, a tendência a atuar em uma direção determinada e a constituição de atitudes emocionais mais estáveis frente à realidade social são fruto de um processo de desenvolvimento do psiquismo como sistema de processos interdependentes ou sistema interfuncional.

Definida a emoção na relação dialética entre corpo e cultura, a qual aponta o caráter simultaneamente biológico e histórico das emoções como traço essencial, coloca-se em pauta a definição de sentimento. Nessa perspectiva, sentimentos são generalizações emocionais, tipos mais estáveis de relação emocional do indivíduo com a realidade. Leontiev (1975) diferencia os sentimentos dos estados emocionais afirmando que

\footnotetext{
Eles [estados emocionais] são os afetos que surgem súbita e involuntariamente (se pode dizer: eu fiquei com raiva, a alegria me dominou); ademais, estas emoções propriamente ditas, são estados primordialmente ideativos e situacionais, com os quais estão relacionados sentimentos objetais, ou seja, utilizando uma expressão figurada de Stendhal, vivências emocionais estáveis, "cristalizadas" no objeto; [...]. Sem entrar na análise destas distintas classes de estados emocionais, assinalemos somente que eles entram em complexas relações mútuas: o pequeno Rostov antes do combate temia - e esta é uma emoção - ser dominado pelo medo; uma mãe pode ficar com raiva de seu filho travesso, sem deixar de amá-lo por um minuto - sentimento (Leontiev, 1975, p. 164).
}

Para a psicologia histórico-cultural, emoções e sentimentos diferem entre si pelo caráter circunstancial e transitório das emoções e o caráter mais estável e duradouro dos sentimentos, que se explica pelo fato de que esses processos se instituem como registros históricos das vivências emocionais que, sustentados por narrativas externas e internas, consolidam essas generalizações em novos fatos 
afetivos, os quais se conservam na esfera motivacional da personalidade. Portanto, emoções e sentimentos só podem ser compreendidos pela dialética entre emoção e conceito: sem a narrativa (significado), as generalizações emocionais jamais se desenvolveriam. Juízos sobre a realidade elaborados historicamente abarcam a aceitação ou a rejeição dessa realidade, ou partes dela, no que se incorporam reações emocionais. Desta forma, emoções e sentimentos compõem o sentido teleológico da atividade na qual o sujeito se inclina com especificidades, sem perder a interfuncionalidade entre os processos psíquicos.

Pelo exposto até aqui, tem-se que as emoções são a base da esfera afetiva da atividade humana, complexificam-se nela e ao mesmo tempo as regulam conforme as condições objetivas e subjetivas dadas a cada instante. Para a psicologia histórico-cultural, situar as emoções e os sentimentos na estrutura e na dinâmica da atividade é fundamental para superar as teorias que dicotomizam emoção - como a expressão de um processo natural ou inferior - e sentimento como expressão de processos espirituais ou superiores. Importa assim entender que ambos os processos se desenvolvem e se complexificam mutuamente em conformidade com a apropriação da cultura.

Um desdobramento fundamental da compreensão de emoções e sentimentos é identificar suas expressões no desenvolvimento da personalidade. $\mathrm{Na}$ relação do indivíduo com a realidade, as emoções e os sentimentos participam decisivamente do processo de atribuição de significado aos objetos, fenômenos e às pessoas, instituindo vivências, isto é, sínteses particulares das dimensões objetiva e subjetiva dessa relação. As inclinações para um ou outro objeto, fenômeno ou pessoa e o processo de antecipação emocional diante de uma ou outra circunstância revela o percurso das escolhas, das relações pessoais, determinados por um espaço e tempo históricos, bem como classe social, religião etc. de cada sujeito (Batista, 2019). Se se considera, assim como pronunciou Bozhovich (1985), que a personalidade não é outra coisa senão o sistema de atividades que cada sujeito realiza dentro das possibilidades concretas da realidade, é importante 
atentar para o fato de que essas atividades estão sob a influência dos diversos complexos sociais 6 .

\section{O conceito de valor e suas origens: dos valores econômicos aos sociais}

Como as emoções e os sentimentos, o problema dos valores sociais é pouco estudado na psicologia vigotskiana. Quase a totalidade do debate sobre o desenvolvimento moral que repercute no Brasil hoje se referencia em Piaget, que com o clássico "O juízo moral na criança"7 (1994) baliza as discussões sobre esse tema. Mas o objetivo aqui não é falar da perspectiva piagetiana. Existem análises muito interessantes do desenvolvimento moral que são menos conhecidas e não repercutem tanto quanto as teses do referido autor, como as de Bozhovich (1987), que trata do desenvolvimento moral como um dos momentos mais importantes da formação da personalidade, que é o seu objeto de pesquisa. Bozhovich descreve o percurso de incorporação dos valores destacando seus impactos na personalidade da criança, sem perder de vista as bases históricas e sociais desse processo. A partir de uma síntese da ontologia marxista, elaborada por Lukács, e da psicologia histórico-cultural, pretende-se explicar aqui o que são os valores sociais, como se desenvolvem as conviç̧ões morais, e ainda qual a sua relação com o conhecimento e com a vida afetiva.

Os valores sociais são qualidades historicamente desenvolvidas pelo ser humano, que são atribuídos a objetos, fatos, pessoas, ações, e retroagem sobre o ser posicionando-o frente às condições e possibilidades de escolhas exigidas pela atividade. Neves (2018), que se dedicou ao estudo dos fundamentos ontológicos dos valores sociais baseado no materialismo histórico-dialético, define valor social como:

\footnotetext{
6 A partir de Lukács (2013), complexos sociais podem ser entendidos como sínteses de determinações que compõem as práxis sociais como o direito, a filosofia, as ciências, a religião, etc. Por isso, Lukács se refere ao desenvolvimento da realidade social como um "complexo de complexos", ou seja, o desenvolvimento das relações humanas tende a se tornar cada vez mais mediado pela cultura, pela práxis social.

${ }^{7}$ Uma discussão sobre o assunto pode ser encontrada em Mesquita (2018, p. 55).
} 
Os valores sociais, por sua vez, não são efetivamente "produtos" da atividade humana, são elementos das relações sociais, próprios das atividades entre os sujeitos. $\mathrm{O}$ valor é um elemento da valoração, da avaliação, do julgamento no pôr teleológico que, diante de uma necessidade e pautado em determinado conhecimento sobre o ser, escolhe entre alternativas consideradas valorosas diante de um dever-ser, de um objetivo. Em se tratando de valores sociais, não se trata do valor de um objeto ou serviço, mas do que se considera valoroso ou desvaloroso na conduta humana, uma determinação própria das relações sujeito-sujeito, isto é, do sujeito com a objetividade social. Os valores sociais são elementos do pôr teleológico que são intimamente vinculados ao conhecimento da realidade, do passado e do presente do ser, e também ao dever-ser, isto é, do que se deseja, que se tem como horizonte desejável. Por isso, os valores estão intimamente relacionados à práxis ativa, que põe a realidade em movimento a partir de valorações entre alternativas (Neves, 2018, p. 30).

Portanto, segundo o autor, os valores sociais são desdobramentos da avaliação moral, do que cada sujeito considera bom ou ruim, certo ou errado, belo ou feio, justo ou injusto, etc. Os valores sociais expressam o posicionamento social dos sujeitos frente às diversas disputas postas pelas relações sociais, e justamente por serem relativos a esse posicionamento, medeiam a forma como o mundo afeta as pessoas, levando-as para além da compreensão distante de um fato, fazendo-as vivenciá-lo. Assim, se os valores são conteúdos da avaliação moral e envolvem conceitos complexos como beleza e justiça, têm uma dimensão nitidamente intelectiva. Ao mesmo tempo, os valores mobilizam reações emocionais e sentimentais, sem perder seu caráter lógico. Esse é justamente o ponto mais forte de uma perspectiva dialética da psicologia, a capacidade de entender os valores como estados emocionais fundidos a juízos intelectuais. Os valores são, portanto, tão intelectuais quanto sensíveis.

Quanto à sua origem histórica, os valores sociais nascem da e na cultura humana. A natureza não produz valores, valoração ou moral em qualquer instância, apenas possui uma objetividade natural que simplesmente existe como é. Em Lukács $(2012 ; 2013)$ a atividade valorativa, base da moral e da ética, nasce do fazer histórico humano, mais especificamente da alternativa do trabalho, ou seja, das escolhas intrínsecas e inalienáveis do processo histórico do trabalho e inaugura, dessa forma, o que aqui se chama valor.

O trabalho gesta novas formas de ação na história: diferentemente dos animais, a atividade humana é marcada pela necessidade de escolha, por fazer 
uma e não outra coisa dentro de um contexto real de circunstâncias. No trabalho há um objetivo e, por meio que se prova funcional e útil, escolhas são feitas para que se alcance o almejado e cada ato do trabalho deve "ser corretamente orientado pelo pôr do fim" (Lukács, 2013, p. 72). As qualidades atribuídas ao que sucede ou fracassa são os valores, que nascem na história, da utilidade das coisas e sua capacidade de satisfazer determinadas necessidades. Assim eles regulam o processo de trabalho, conduzindo escolhas e compondo a determinação ontológica da existência, sem a qual nenhum processo social é possível. Por ocupar esse papel, ele modifica o processo que lhe deu origem, nasce da ação do ser social, mas a toma como objeto, pois a baliza e medeia no processo vivo de aprendizagem e relação do ser com a natureza no trabalho.

A origem dos valores no processo de trabalho nada diz, entretanto, sobre a moral humana, ou seja, os valores econômicos não podem explicá-la, mas a leitura lukacsiana de Marx nos permite pensar uma ontologia ${ }^{8}$ em que o trabalho serve de protoforma às demais atividades humanas, um complexo social do qual nascem outros complexos que dele se diferenciam e autonomizam. Se no trabalho aprendemos a avaliar, a avaliação pôde ser historicamente estendida a outros campos da vida social, e quando ela começa a permear as relações interpessoais, a avaliação se autonomiza e se liberta da mera utilidade para qualificar ações humanas. A esses valores que se desdobram a campos da cultura diferentes da produção, Lukács chama valores sociais, dos quais se origina historicamente a moral, atividade desdobrada dos valores econômicos, que uma vez nascida, igualmente muda o processo que a faz nascer e se coloca como necessidade de avaliação da conduta humana. De acordo com Lukács (2012),

\footnotetext{
A rejeição da hierarquia no terreno ontológico liga-se estreitamente à questão de como o valor econômico se relaciona com os demais valores sociais [...]. Acreditamos que a necessidade social que põe os valores é, com igual necessidade ontológica, ao mesmo tempo pressuposto e resultado do caráter alternativo dos atos sociais dos homens. No ato da alternativa está contida necessariamente também a escolha entre o que tem valor e o que é contrário ao valor; temos assim, por necessidade ontológica, tanto a possibilidade de escolher o que é contrário ao valor
}

\footnotetext{
${ }^{8}$ Como reitera José Paulo Netto no prefácio à Ontologia do ser social (Lukács, 2012).
} 
quanto a possibilidade de errar, mesmo tendo escolhido subjetivamente o que é de valor (Lukács, 2012, p. 409).

Se a ideia de que os valores nascem do fazer humano e sobre ele retroagem é retomada, é possível notar que os valores sociais inauguram as ações por convicção moral, ou a busca pelo agir correto. Nascem sistemas de valores que traduzem visões de mundo, sociedade, natureza, divindade, etc. O agir humano passa a ser objeto de julgamento e deve necessariamente ser enquadrado em um sistema moral, pois não se descola mais do sistema de juízos mantidos pela sociedade. A questão passa a ser quais valores são regentes ou centrais numa certa visão social de mundo, o que recoloca o campo de disputas na história das sociedades de classe: o que é justo e certo para uma classe ou grupo social, não necessariamente o é para outra. Se hoje se vive uma crise de valores, é necessário pensar quais são os valores desejáveis, quais se espera que perseverem como centrais na sociedade em disputa, resgatando a constante reflexão filosófica sobre a moral, que Vázquez (2005) define como ética. Resta agora pensar como o desenvolvimento moral opera na vida subjetiva, no desenvolvimento concreto das pessoas. Para isso faz-se necessário entender o desenvolvimento dos valores articulado ao desenvolvimento psíquico em geral, às mudanças estruturais da atividade, da motivação, do papel da criança nas relações sociais e, especialmente, as transformações no campo do pensamento, emoções e sentimentos.

\section{Emoções, sentimentos e valores sociais na periodização do desenvolvimento psíquico}

A periodização do desenvolvimento psíquico na psicologia histórico-cultural vem produzindo principalmente, até o momento, análises sobre as atividadesguia, isto é, as atividades que promovem o desenvolvimento psíquico em cada período, de acordo com o trabalho de Elkonin (2017). Convém destacar que os períodos apresentados a seguir não são naturais, portanto nem universais, mas foram identificados no contexto histórico-cultural da União Soviética e são adotados apenas como referência para a promoção do desenvolvimento no contexto brasileiro, o que significa dizer que nem sempre a situação social e as 
condições de vida das crianças e adolescentes favorecem a formação dos motivos e a estruturação das atividades que deveriam guiar o seu desenvolvimento. Ainda assim, os estudos acerca de cada atividade possibilitam avançar sobre algumas particularidades do desenvolvimento até agora pouco exploradas, como o percurso do desenvolvimento das emoções e dos sentimentos em relação com os valores sociais. Dessa forma, o presente estudo corresponde a uma aproximação do tema, restando necessárias a realização de aprofundamentos teóricos e a coleta de dados empíricos, o que indica o atual estado do desenvolvimento da teoria.

Ao realizar uma sistematização dos estudos sobre a periodização, incorporando principalmente os estudos de Leontiev sobre a atividade e de Vigotski sobre o desenvolvimento do psiquismo, Elkonin pontua que o conceito de atividade "permitiu mudar radicalmente tanto as noções sobre as forças propulsoras do desenvolvimento psíquico, quanto os princípios de divisão de seus estágios" (Elkonin, 2017, p. 153). A incorporação das leis gerais da periodização tem como objetivo fundamentar o percurso do desenvolvimento das emoções e dos sentimentos e a formação da instância moral da personalidade a partir dos valores sociais.

Bozhovich (1987) mostra que há uma periodização básica a seguir para compreender o nascimento das instâncias morais da personalidade. $\mathrm{O}$ movimento geral é o próprio nascimento do julgamento moral a partir das vivências emocionais. Tudo indica que o solo sobre o qual nascem as convicções morais complexas, estruturantes da personalidade, é a necessidade de manter nosso bem estar emocional. As primeiras avaliações da criança pequena são dominadas pelo equilíbrio emocional e não pelo julgamento lógico e consequente. Do solo emotivo, contudo, elas se transformam radicalmente, desenvolve-se paulatinamente a capacidade de pensar objetivamente, a partir de dados da realidade. Daí, pelas próprias forças das relações interpessoais, aparece a necessidade de compreender e pensar sobre bem e mal, justo e injusto, etc., discernir entre eles, posicionar-se e implicar-se com o próprio posicionamento. Tal movimento, aqui abreviado, da avaliação inicial até a formação das conviç̧ões morais mais elaboradas, percorre quase todos os períodos estudados por Elkonin (2017), desde o período objetal- 
instrumental (ou objetal-manipulatório) até a comunicação íntima-pessoal, conforme se verá a seguir.

\title{
Primeiro ano de vida
}

Para Vigotski, o desenvolvimento humano se inicia no nascimento. Segundo ele, "o desenvolvimento da criança começa pelo ato crítico do nascimento e a idade crítica que lhe segue, que se denomina pós-natal” (Vygotski, 1996, p. 275). Dessa forma, os primeiros dias de vida da criança são marcados por uma crise de transição do período intrauterino ao extrauterino. Nesse período crítico a/o bebê é caracterizada/o psicologicamente pela fusão dos processos sensoriais, emocionais e motores no que Vigotski denomina de amálgama sensório-motor. Esta é a gênese da vida psíquica, ou seja, o ponto de partida da complexificação do psiquismo, pela atividade social. De acordo com Vigotski,

\begin{abstract}
Não há ideias inatas ou percepção real no recém-nascido, isto é, a compreensão de objetos e processos externos nem, finalmente, desejos ou aspirações conscientes. A única coisa que podemos admitir com alguma base é a existência de estados de consciência nebulosos e confusos, nos quais o sensível e o emocional se fundem a tal ponto que podemos qualificá-los como estados emocionais sensíveis ou estados emocionalmente marcados de sensações. A existência de estados emocionais agradáveis ou desagradáveis já se manifesta nos primeiros dias de vida da criança, na expressão de seu rosto, na entonação de seus gritos, etc. (Vygotski, 1996b, p. 281-2, grifos nossos).
\end{abstract}

A complexidade do psiquismo humano tem origem no ser orgânico, é herança da evolução das espécies, e isso é notadamente importante para a análise das emoções. Como evidencia Vygotski (1996b, p. 280), os "instintos e afetos mais simples dependem, provavelmente, de forma mais direta, dos centros subcorticais que, em certa medida, já funcionam no recém-nascido". Com isso, é possível afirmar que a vida psíquica individual tem matriz emocional e as neoformações psíquicas surgem a partir do amálgama originário sensações-emoçõesmotricidade. Esse amálgama se transforma na medida em que a/o bebê começa a estabelecer relações com outras pessoas, demandando de seu psiquismo uma relação ativa e mediada com o meio social, pois a relação interpessoal é sempre mediada por signos. Isso significa, em termos de transformação do psiquismo, que 
o amálgama original se rompe dando início à diferenciação das funções psíquicas, ou seja, cada função começa a adquirir uma independência relativa, dado que se preservam vínculos interfuncionais, os quais se transformam no processo de desenvolvimento. Em suma, como diz Vygotski (1995), o mecanismo geral do desenvolvimento é de diferenciação interna e interfuncionalidade crescentes.

Já no primeiro ano de vida se inicia a superação dos limites naturais do psiquismo humano na atividade de comunicação da/o bebê, a qual atende a uma necessidade natural, na medida em que a/o bebê depende totalmente dos cuidados de outras pessoas para sobreviver. É essa dependência natural que caracteriza a/o bebê como ser social desde o nascimento, fazendo necessárias as mediações sociais na sua relação com o meio.

Destaca-se no desenvolvimento das emoções no primeiro ano de vida o aparecimento do complexo de animação, quando a/o bebê sorri impetuosamente diante de outra pessoa e movimenta com rapidez os braços e as pernas, o que para Bozhovich (1978) representa um salto na qualidade de comunicação da/o bebê com outras as pessoas. A intensidade da expressão emocional da/o bebê neste momento se deve, segundo essa autora, à satisfação da necessidade de "aspiração a uma nova vivência" (Bozhovich, 1978). Isso significa que além de estar satisfazendo suas necessidades mais vitais, as pessoas engendram a possibilidade de a/o bebê adquirir novas necessidades, chamada pela autora de necessidade de impressões externas (sociais). Assim, conforme as pessoas possibilitam à criança a apropriação de novas impressões externas através da comunicação, mais ativa é a ação da/o bebê para com o meio social, os objetos e as relações sociais. Esse processo representa o desenvolvimento da comunicação emocional direta da/o bebê com as pessoas ao seu redor, atividade-guia do primeiro ano de vida, na qual as emoções já passam por um processo de transformação exigida pela própria atividade.

\section{Primeira infância}

Quando, no primeiro ano de vida, a/o bebê vislumbra os objetos que medeiam sua relação com as outras pessoas, surgem os motivos que orientam e 
estruturam, na primeira infância, a atividade objetal-instrumental como guia do desenvolvimento:

\begin{abstract}
Desta forma, pois, as ações objetais surgem no contexto da comunicação das crianças com os adultos. Porém, logo elas adquirem uma relativa independência com respeito à atividade comunicativa e têm sua própria linha de desenvolvimento, ligada com a comunicação mas já não fundida com ela. Entre a atividade objetal e a comunicação se estabelecem relações complexas. Em casos favoráveis a comunicação se converte em parte ou aspecto da atividade manipulatória; a colaboração com o adulto, o exemplo ativo e o apoio prático dos maiores ajudam a criança a dominar os jogos processuais e assimilar os procedimentos socialmente fixados para utilizar objetos cotidianos simples (vasilha, vestimenta, etc.) (Lísina, 1987, p. 290).
\end{abstract}

O uso instrumental dos objetos e o crescente interesse por eles exigem da criança a requalificação da comunicação. É através da manipulação exploratória e da fala que a criança se apropria da função social dos objetos e de seus valores sociais que os revestem na prática social. Nesse período, a ação da criança passa a não depender totalmente da intensidade da estimulação oriunda dos objetos externos. Mesmo que incipientemente, a criança começa a atentar, sentir, perceber, ser afetada pelos objetos e a desejá-los por seus significados, por seu valor social.

A atividade objetal-instrumental engendra a formação da capacidade de a criança avaliar os objetos por meio de critérios ainda frágeis, porém dotados de elementos objetivos. Considerando que a criança utiliza os objetos para se manter inserida nas relações sociais, sua carga social e a avaliação do seu uso feita por outras pessoas têm impacto significativo no desenvolvimento infantil - dimensão técnica, ética, estética, etc. A criança não aprende simplesmente a utilizar tecnicamente uma vassoura, por exemplo, pois esse objeto faz parte de contextos sociais concretos. Em seu ambiente doméstico, se não interrompido o ciclo hegemônico da distinção social de gênero, a criança verá mais frequentemente mulheres utilizando este objeto. Já no contexto escolar ou no ambiente de trabalho o uso da vassoura, se superarmos sua aparência fenomênica, pode levar à compreensão da divisão social existente entre trabalho manual e intelectual. Obviamente que a criança não apreende a complexidade das determinações que compõem os objetos, a apropriação de seus significados são requalificados a cada idade, mas mesmo que as crianças não apreendam essas relações de forma 
intelectualmente complexa, sua imitação aparecerá nas brincadeiras de papéis sociais.

Ainda nesse período, além da avaliação dos objetos, dotados de valor social, a avaliação da criança começa a se voltar para si mesma. Bozhovich (1987) se apoia em investigações para afirmar que nessa idade as crianças principiam uma espécie de autoavaliação bastante simples estruturalmente e carente de todo elemento lógico, motivo pelo qual esse processo não pode ser chamado de avaliação propriamente dita. Contudo as crianças demonstram ser capazes de julgar a si mesmas emocionalmente, tratando de conseguir receber aprovação das pessoas adultas e de manter assim seu bem estar emocional. Por isso seus dados experimentais atestam que as crianças geralmente se avaliam como boas e certas, independentemente do que tenham feito, avaliando-se a partir de elementos externos às suas ações.

\section{Idade pré-escolar}

$\mathrm{Na}$ idade pré-escolar a criança se torna sensível à consideração do sucesso ou fracasso advinda do círculo de pessoas mais próximas a ela, ou seja, a criança incorpora à sua autoavaliação a opinião social. A incorporação dos valores sociais às suas necessidades emocionais transforma a estrutura interna de sua atividade. $\mathrm{O}$ pensamento em desenvolvimento e as brincadeiras de papéis sociais levam a criança a observar a realidade social, e a compreensão cada vez mais ampla da realidade permite que se imbriquem novos elementos à valoração, como afirma Bozhovich:

[...] nos pré-escolares se forma uma autovaloração que se apoia na avaliação realizada de uma ou outra maneira, do êxito de suas ações, na valoração dos circundantes, na aprovação dos pais. Pode-se dizer que na infância pré-escolar se forma realmente uma particular visão infantil de mundo, na que entra certa representação geral sobre o mundo, a atitude frente a ele e a si mesma no dito mundo (Bozhovich, 1987, p. 270-1).

Dessa forma, entende-se que é na idade pré-escolar, no contexto das brincadeiras de papéis e da comunicação social, que nasce na criança uma instância propriamente moral de sua personalidade, ainda que simples enquanto formação sistêmica do psiquismo. 
A necessidade de se inserir nas relações entre pessoas adultas, "fazer o que o adulto faz", sem a possibilidade de realizar objetivamente a mesma atividade, a atividade de trabalho, encontra satisfação na brincadeira de papéis sociais, a qual dessa forma se institui como a atividade-guia desse período do desenvolvimento. É nesse contexto que se unem às vivências emocionais da criança o conhecimento de certas regras e normas sociais, bem como a avaliação da relevância das atividades sociais, ainda vividas de forma bastante emotiva, mas já carregadas de elementos socialmente objetivos. Outro ponto de destaque é o que Elkonin (2017) chamou de necessidade imperativa de obedecer ao papel, quando se julga ativamente a forma correta de desempenhar o papel, ação eminentemente avaliativa. Em suma, seguindo a ideia da transformação cultural das emoções, o próprio nascimento dos papéis sociais, interpretados nas brincadeiras, atesta a nova composição das necessidades emocionais da criança, mais lógicas e progressivamente permeadas de conteúdo social. No exercício da escolha dos enredos e papéis das brincadeiras, as crianças exercitam as normas gerais da sociedade que as afetam mais, de acordo com os seus contextos sociais imediatos. Por isso, podem ser observados os primórdios das conviç̧ões morais futuras.

Diante dessas considerações, também é possível afirmar que é na idade pré-escolar que surgem os primeiros sentimentos, justamente porque nesse período ocorrem as primeiras formas de generalização das vivências emocionais. $\mathrm{Na}$ medida em que a criança passa a ter preocupação com o impacto das suas ações sobre si mesma e sobre o seu grupo social, ela tende a reproduzir ações socialmente valorizadas que geram, consequentemente, reconhecimento pessoal e emoções positivas vinculadas à satisfação de necessidades sociais. Para Elkonin (2009) a brincadeira de papéis representa a evolução da esfera das motivações e necessidades da personalidade da criança. Para brincar a criança se orienta afetivamente para um papel social: suas emoções, além de expressar um conteúdo motivacional, também atuam para a realização desses motivos, balizando-se nas possibilidades de relações sociais conhecidas por ela.

As condições e as relações sociais a que a criança tem acesso em sua vida concreta são as fontes de conteúdo das brincadeiras de papéis. O conteúdo emocional origina-se das condições sociais concretas vividas pela criança e se 
constitui como um importante elemento orientador da atividade, atribuindo-lhe caráter motivador. Esta constatação é feita por Elkonin (2009) ao tratar das possibilidades de relações que podem ser estabelecidas na brincadeira:

\begin{abstract}
Claro que o caráter concreto das relações entre as pessoas representadas no jogo é muito diferente. Essas relações podem ser de cooperação, de ajuda mútua, de divisão do trabalho e de solicitude e atenção de uns com os outros; mas também podem ser relações de autoritarismo, até despotismo, hostilidade, rudeza, etc. Tudo depende das condições sociais concretas em que vive a criança (p. 35).
\end{abstract}

Essa discussão coloca em questão as diversas posições morais que se apresentam como possibilidades de realização da atividade. As alternativas são dadas pelas condições objetivas e as escolhas pelas identificações valorativas. $\mathrm{Na}$ sociedade de classes os valores nunca são universais, pois são resultados de disputas históricas entre grupos antagônicos. A disputa por valores também é incorporada na brincadeira infantil. Quando a brincadeira exige representações de gênero, por exemplo, existem basicamente dois valores em disputa: a reprodução da desigualdade de gênero contra a emancipação feminina das relações de dominação patriarcais. Portanto, o desenvolvimento das emoções e dos sentimentos na relação com os valores sociais é decisivo na formação da personalidade da criança. No período pré-escolar do desenvolvimento, emana cada vez mais o sentido moral da personalidade.

\title{
Idade escolar
}

A passagem para a idade escolar é marcada pelo acesso da criança a formas cada vez mais desenvolvidas de pensamento e atividade. Tão logo as capacidades de ação e compreensão da criança aumentam, ela mesma muda. Sua atividade se transforma, as brincadeiras de papéis dão lugar aos jogos de regras e a imitação perde sua eficiência para satisfazê-la emocionalmente. A criança sente que pode fazer o que as pessoas adultas fazem, que não é mais criança e que pode fazer tudo, como "gente grande". É na passagem das brincadeiras dramáticas à atividade de estudo que a criança muda de lugar nas relações sociais e deve assumir responsabilidades, exigindo-se dela a realização de novas tarefas, conquistas, alterando-se consequentemente a sua percepção de si mesma. 
Escolarizar-se é o destino mais comum no contexto social atual para satisfazer a necessidade de saber e fazer o que as pessoas adultas sabem e fazem, do que decorre a instituição da atividade de estudo como nova atividade-guia do desenvolvimento. Ocorre, porém, que a entrada na escola por si só não garante a instituição da atividade de estudo como guia do desenvolvimento, pois para isso é essencial que a aquisição de conhecimento se torne uma necessidade da criança e que ao mesmo tempo a escola se mostre capaz de satisfazer essa necessidade. A formação dessa necessidade, por sua vez, depende da importância que os conhecimentos possuem nas relações interpessoais que a criança estabelece, por isso é importante que a escola valorize os conhecimentos produzidos sistematicamente como formas mais desenvolvidas de compreensão da realidade, sem relativizá-los. Tendo em vista que o psiquismo se caracteriza como unidade afetivo-cognitiva, na medida em que as crianças são privadas de conhecimentos artísticos, científicos e filosóficos, fica comprometida não apenas a sua formação intelectual, mas também o seu desenvolvimento emocional.

Com a instituição da atividade de estudo como atividade-guia e, portanto, com a mudança do período de desenvolvimento, diferencia-se o campo interno da vivência da criança, levando a uma reorganização brusca das suas formas de relacionamento com o mundo, outras pessoas e consigo mesma, configurando-se assim a crise dos sete anos (Vygotski, 1996b). É como se a criança compreendesse que sua existência no mundo é mediada pelo que ela percebe, pelo modo como o mundo se manifesta nela. Em outras palavras, é como se ela pudesse diferenciar o campo objetivo e subjetivo de suas experiências, o que é externo do que é interno a ela. A partir de então, a criança perde a espontaneidade que caracteriza a idade pré-escolar, podendo adotar posturas dissimuladas e jocosas para com outras pessoas. Todavia, mais importante que isso é que as capacidades de autoobservação e autoavaliação se tornam possíveis pela introspecção. Segundo Vigotski, "surge [na criança] a orientação consciente de suas próprias vivências" (Vygotski, 1996b, p. 380), o que permite que ela passe a ter vivências de suas próprias vivências.

É nessa crise que nasce na criança a reflexão consciente e as instâncias propriamente morais de sua personalidade, pois a criança pode comparar pontos 
de vista e observar seus estados internos, suas próprias crenças e valores nascentes. A crise dos sete anos inaugura a possibilidade da reflexão ética, o que é central para o desenvolvimento das convicções morais que se tornarão fortes parâmetros das escolhas futuras.

\section{A adolescência}

A psicologia da educação aponta a transição para a adolescência como um momento de grande importância no desenvolvimento do pensamento. No período anterior, correspondente ao ensino fundamental, o rol de conhecimentos da criança cresce expressivamente, de tal forma que a passagem à adolescência é marcada pelas forças acumuladas que culminam na mudança estrutural do pensamento e das motivações da juventude. $\mathrm{O}$ pensamento se desenvolve adquirindo independência das referências sensoriais diretas, passando a trabalhar confortavelmente com abstrações, hipóteses e deduções puras. Surge o pensamento conceitual, categórico, que permite às/aos adolescentes uma compreensão mais aprofundada de seu próprio mundo social, capaz de superar a aparência dos objetos e fenômenos da realidade, apreendendo a sua essência. Segundo Vigotski (1996a), na adolescência, que ele denomina "idade de transição", nascem os interesses por política e música (arte mais abstrata), o que revela o surgimento da possibilidade de se compreender a vida em sociedade, na acepção mais ampla possível desse conceito.

Tais novidades são elaboradas na atividade-guia do período, a comunicação íntima-pessoal. O mais importante nesse momento são as novas vinculações entre adolescentes, marcadas pelo desenvolvimento físico acentuado e pelo amadurecimento sexual, bem como por um novo tipo de engajamento na vida grupal. Na sociedade soviética observava-se nesse período o exercício de relações de companheirismo, respeito mútuo, amizade e comunidade da vida interior entre as/os jovens, por onde se arquitetam relações de identificação e diferenciação. $\mathrm{Na}$ sociedade capitalista, que converte as pessoas em mercadorias, tratando-as eufemisticamente como "capital humano", produzem-se relações distintas, baseadas na competição e no individualismo. Nas novas atividades, um código moral especial é vivenciado, aplicado às suas próprias vidas, no qual 
inevitavelmente se reproduzem, muitas vezes de forma criativa e crítica, as principais formas de atividade social (Elkonin, 1987).

Dragonova (1973) afirma que as relações entre os pares, nesse momento do desenvolvimento, desempenham uma função importante para a formação dos valores e da personalidade dos adolescentes:

Quanto mais ricos são os vínculos coletivos do adolescente e mais se amplia sua colaboração com seus pares e com os adultos nos distintos aspectos das atividades socialmente úteis, maior a quantidade de valores socialmente significativos que têm para assimilar e mais rica será sua personalidade (p. 138).

No auge do desenvolvimento da adolescência, na confluência de um novo tipo de pensamento, de novas relações íntimas entre coetâneas/os e do exercício de uma moralidade dos grupos aos quais pertence, nascem finalmente na personalidade as primeiras convicções morais propriamente ditas, que são organizadas na visão social de mundo, a neoformação típica da adolescência, segundo Bozhovich (1985). Assim, a personalidade ganha novos contornos, nos quais os valores e a conviç̧ões morais se sistematizam na visão que as/os adolescentes têm do mundo, de si, da sociedade, etc. Em outras palavras, a moralidade não só nasce na plenitude da unidade entre a história das vivências emocionais e a compreensão intelectual do mundo, a qual possibilita o julgamento lógico dos fatos, mas também define os traços essenciais de uma personalidade desenvolvida. Assim, as valorações sociais são incorporadas no curso do desenvolvimento e se tornam instrumentos da gradativa reestruturação do sistema psíquico e da formação da personalidade, colocando-se como mediadoras da relação do sujeito com o mundo e engendrando a dinâmica da esfera afetivaemocional da atividade.

\section{Considerações finais}

A educação formal pode e deve se preocupar com o desenvolvimento emocional, sentimental e a formação de valores das novas gerações, e por isso pode e deve tratar valores como conteúdo pedagógico, bem como criar condições para que haja consciência e elaboração de emoções e sentimentos na escola. Isso, 
todavia, não é algo simples, e pode facilmente se converter em perigosa armadilha. Uma análise histórica nos mostra que a educação emocional e moral não é novidade, ocorre nas escolas, mas tem em geral caráter político reacionário, preparam a subordinação de classe e a adaptação à ordem vigente, ou seja, são subordinadas aos interesses da classe dominante. Vigotski, já na década de 1920 criticava a educação moral burguesa oferecida pelas escolas:

\begin{abstract}
Até onde ela [a educação moral tradicional] se revelou na criação da sua força e do seu poder, onde obteve êxitos plenos, mesmo ali revelou que é capaz apenas de criar uma criança bem intencionada e cautelosa, pusilânime e propensa à subordinação, obediente e covarde. E isso deviase ao fato de que todo o sistema de educação moral se baseava em um princípio autoritário dos pais ou mestres, sentido esse mantido pela sanção da recompensa e do castigo, da intimidação e do bem-estar. "Obedecei aos mais velhos e te darás bem, do contrário te darás mal". Eis a fórmula grosseira porém precisa dessa pedagogia (Vigotski, 2010, p. $313)$.
\end{abstract}

A educação moral já experimentada é a que interessa às classes dominantes, a da obediência, do respeito à autoridade irrefletido, da hierarquia social, tendo o medo como emoção central. E Vigotski complementa, "a educação moral em cada escola coincide inteiramente com a moral da classe que orienta a escola" (idem, p. 296). Em uma sociedade marcada pela dominação entre classes, é mais conveniente ensinar a obedecer que ensinar a escolher de forma politizada e socialmente consequente. Essa é a armadilha de defender sem cuidados a educação emocional ou a formação moral. No Brasil, por exemplo, temos a experiência da Educação Moral e Cívica (EMC), que marcou o currículo nacional durante a ditadura civil-militar. Nascida em $1925^{9}$, sua história é de entrada e saída do currículo oficial, tendo várias versões até se consolidar em 1969 (Decreto-lei $\mathrm{n}^{\circ}$ 869/1969) como resposta às manifestações contra o Ato Institucional $\mathrm{n}^{\circ} 5$ (AI-5), que tomaram o país. A EMC refletia a formação moral na ditadura ao impor seus padrões de civilidade e cidadania. Filgueiras (2006) sustenta que a EMC representava o "liberalismo, conservadorismo, romantismo,

\footnotetext{
${ }^{9}$ Segundo Frediani e Honorato (2017, p. 547), em “1925 através da Reforma 'Rocha Vaz' passou a fazer parte do currículo obrigatório do Ensino Secundário sob o título de Instrução Moral e Cívica".
} 
catolicismo, positivismo e a doutrina da segurança nacional" (p. 4), cujos valores centrais são a propriedade privada, a conservação de privilégios, a obediência, o nacionalismo, entre outros. Conhecer seus valores serve para orientar no sentido oposto, ou seja, no sentido da construção de uma educação emancipadora cujos valores são a igualdade, a justiça, a verdade e a liberdade.

$\mathrm{Na}$ defesa da educação emocional o risco é o mesmo: historicamente, a preocupação com as emoções e os sentimentos dos/as estudantes surge com a crescente influência da psicologia na educação e os movimentos escolanovistas já no final do século XIX e início do século XX, o que atesta a relevância dessa discussão. Patto (2000) identifica na história da educação várias tentativas de emplacar a educação emocional como instrumento de controle social, sob aparências e justificativas variadas, as quais ela designa como "mutações do cativeiro". Na década de 1990, por exemplo, o debate prospera em torno da ideia de inteligência emocional, quando escolas e principalmente empresas começam a valorizar qualidades emocionais e a capacidade de empregar emoções e sentimentos no trabalho e no "exercício da cidadania", expressão utilizada para ocultar a dominação de classe que sustenta o capitalismo (Patto, 2000). Desde 2011, no Brasil, está em curso a elaboração de currículos orientados para a formação de competências que incorporam, por influência de agências internacionais e organizações da sociedade civil, como a Organização para a Cooperação e Desenvolvimento Econômico (OCDE) e o Instituto Ayrton Senna (IAS), a formação de competências não cognitivas ou socioemocionais pelo treinamento de comportamentos e reações emocionais mais adaptadas aos diversos contextos sociais, naturalizando-se as relações de dominação que caracterizam a sociedade capitalista (Silva, 2018).

Mas, se os limites de superação das formas de organização social pela educação são evidentes, isso conduz aos seguintes questionamentos, frequentes nas discussões pedagógicas: a educação escolar está fadada a reproduzir os fundamentos da sociedade na qual se insere? É possível uma educação revolucionária na sociedade capitalista, ou ela só será alcançada com a revolução social? As respostas, ainda que não sejam unânimes, devem contemplar o papel 
da escola na formação dos valores sociais e no desenvolvimento de emoções e sentimentos suscitados na relação de cada indivíduo com a sociedade burguesa.

Silva (2018), por exemplo, conclui que o papel da escola na socialização dos conhecimentos historicamente sistematizados não se vincula apenas à formação intelectual das/os estudantes, mas também à formação de uma recepção emocionalmente crítica da sociedade do capital, gerando uma disposição afetiva nas pessoas contra as injustiças e a brutalidade que o capitalismo necessariamente impõe à classe trabalhadora, como na epígrafe escolhida para este texto, em que Ernesto Guevara incita suas/seus filhas/os a "sentir no mais profundo de vocês qualquer injustiça cometida contra qualquer pessoa em qualquer parte do mundo", numa solidariedade humana radical, que ele vê como uma das maiores qualidades de uma pessoa revolucionária. Portanto, ele se refere a uma postura sentimental e valorativa.

Mas como criar as condições para a educação emocionalmente crítica? Essa resposta ainda está pode ser lapidada, mas um caminho possível é pensar as relações intersubjetivas na escola, no sentido de romper com formas de sociabilidade competitivas e individualistas, alterando pedagogicamente as relações e formando coletivos em torno de interesses políticos emancipatórios. Se os valores sociais internalizados carregam tanto a história sentimental de uma pessoa quanto sua compreensão intelectual da realidade, a educação crítica deve se ater à dialética das funções afetivas e cognitivas como um dos caminhos para gerar processos reflexivos e produzir novas práticas dentro do espaço escolar e, como consequência, práticas transformadoras da sociedade.

\section{Referências}

BATISTA, J. B. O desenvolvimento de emoções e sentimentos na infância como fundamento psicológico da educação escolar. 2019. 121 f. Dissertação (Mestrado em Educação Escolar). Faculdade de Ciências e Letras, Unesp de Araraquara, Araraquara, 2019. 
BOZHOVICH, L. I. El problema del desarrollo de la esfera motivacional em el niño. In: BOZHOVICH, L. I.; BLAGONADEZHINA, L. (org.). Estudio de la motivación de la conducta de los niños y adolescentes. Moscú: Editorial Progreso, 1978.

BOZHOVICH, L. I. La personalidad y su formación en la edad infantil. Habana: Editorial Pueblo y Educación, 1985.

BOZHOVICH, L. I. Las etapas de formación de la personalidad en la ontogénesis. In: DAVÍDOV, V; SHUARE, M. (org.). La Psicología Evolutiva y Pedagógica en la URSS: Antología. Moscú: Editorial Progreso, 1987.

DRAGONOVA. Caracteristicas psicológicas del adolescente. In: PETROVSKI (org.). Psicologia evolutiva y pedagógica. Moscú: Editorial Progreso, 1973.

ELKONIN, D. B. Psicologia do jogo. 2. ed. São Paulo: Martins Fontes, 2009.

ELKONIN, D. Sobre el problema de la periodización del desarrollo psíquico en la infancia. In: DAVÍDOV, V; SHUARE, M. (org.). La Psicología Evolutiva y Pedagógica en la URSS: Antología. Moscú: Editorial Progreso, 1987.

ELKONIN, D. Sobre o problema da periodização do desenvolvimento psíquico na infância. In: LONGAREZI, A. M.; PUENTES, R. V. (org.). Ensino desenvolvimental: antologia: Livro I. Uberlândia, MG: EDUFU, 2017.

FILGUEIRAS, J. M. A educação moral e cívica e sua produção didática: 19691993. Dissertação de mestrado em educação. PUC/SP, 2006.

FREDIANI, D. C.; HONORATO, T. A disciplina de educação moral e cívica na ditadura militar: um estudo sobre o ideal de homem civilizado presente nos livros didáticos. Anais Eletrônicos do IX Congresso Brasileiro de História da Educação, João Pessoa (UFPB), 15 a 18 de agosto de 2017, 2017.

LEONTIEV, A. N. Actividad, consciencia y personalidad. Havana: Editorial Pueblo y Educación, 1975.

LEONTIEV, A. N. As necessidades e os motivos da atividade. In: LONGAREZI, A. M.; PUENTES, R. V. (org.). Ensino desenvolvimental: antologia: Livro I. Uberlândia, MG: EDUFU, 2017.

LÍSINA, M. La génesis de las formas de comunicación en los niños. In: DAVYDOV, Vasili; SHUARE, M. La psicología evolutiva y pedagógica en la URSS: antología. Moscú: Editorial Progreso, 1987.

LUKÁCS, G. Para uma ontologia do ser social, I. São Paulo: Boitempo, 2012.

LUKÁCS, G. Para uma ontologia do ser social, II. São Paulo: Boitempo, 2013. 
MESQUITA, A. M. A formação psicológica de valores morais no contexto da sociabilidade competitiva e individualista na educação: apontamentos para a atividade pedagógica. $175 \mathrm{f}$. Tese (Doutorado em Educação). Faculdade de Ciências e Filosofia, Unesp de Marília, Marília, 2018.

NEVES, J. C. T., Valores sociais, educação e resistência: fundamentos ontológicos e contradições históricas. 187 f. Dissertação (Mestrado em Educação). Faculdade de Educação, Unicamp, Campinas/SP, 2018.

PATTO, M. H. S. Mutações do cativeiro: escritos de psicologia e política. São Paulo: Edusp, 2000.

PIAGET, J. O juízo moral na criança. São Paulo: Summus Editorial, 1994.

SILVA, M. M. A formação de competências socioemocionais como estratégia para captura da subjetividade da classe trabalhadora. 2018. 169 f. Tese (Doutorado em Educação Escolar). Faculdade de Ciências e Letras, Unesp de Araraquara, Araraquara, 2018.

VÁSQUEZ, A. S. Ética. Barcelona: Editora Crítica, 2005.

VIGOTSKI, L. S. O método experimental em psicologia. In: Teoria e método em psicologia. 3. ed. São Paulo: Martins Fontes, 2004a.

VIGOTSKI, L. S. Psicologia Pedagógica. São Paulo: Martins Fontes, 2010.

VIGOTSKY, L. S. Teoría de las emociones: estudio histórico-psicológico. Madrid: Akal, 2004b.

VYGOTSKI, L. S. Historia del desarrollo de las funciones psíquicas superiores. In: VYGOTSKI, L. S. Obras escogidas: tomo III. Madrid: Visor, 1995.

VYGOTSKI, L. S. Paidología del adolescente. In: VYGOTSKI, L. S. Obras escogidas: tomo IV. Madrid, Visor, 1996a.

VYGOTSKI, L. S. La crisis de los siete años. In: VYGOTSKI, L. S. Obras escogidas: tomo IV. Madrid: Visor, $1996 \mathrm{~b}$. 